\title{
JUVENTUD Y POLÍTICA EN CHILE. HACIA UN ENFOQUE GENERACIONAL
}

\author{
VÍCTOR MUÑOZ TAMAYO*
}

\begin{abstract}
RESUMEN
El texto expone algunos conceptos desarrollados por el sociólogo Karl Mannheim sobre juventud y generaciones, argumentando la actualidad de sus planteamientos, para luego, dar una mirada a la producción sociológica e historiográfica sobre generaciones y política en Chile. Por último, finalizar con una propuesta conceptual para el abordaje del problema de las generaciones en su conexión con las culturas y subjetividades políticas.

PALABRAS CLAVE: MANNHEIM, SUBJETIVIDAD POLÍTICA, GENERACIONES

* Historiador, Doctor en Estudios Latinoamericanos UnAM. Departamento de Sociología de la Universidad de Chile.

Correo electrónico: vmtamayo@u.uchile.cl.

Este texto fue escrito en el marco del proyecto posdoctoral FONDECYT No3110075.
\end{abstract}




\title{
JUVENTUDE E POLÍTICA NO CHILE. PARA UM ENFOQUE GERACIONAL
}

\begin{abstract}
RESUMO
O texto discute alguns conceitos desenvolvidos pelo sociólogo Karl Mannheim sobre juventude e gerações, argumentando a atualidade de seu ponto de vista, para então analisar a produção sociológica e historiográfica sobre gerações e política no Chile, finalizando com uma proposta conceitual para a abordagem do problema das gerações em sua relação com as culturas e subjetividades políticas.
\end{abstract}

PALAVRAS CHAVE: MANNHEIM, SUBJETIVIDADE POLÍTICA, GERAÇÕES

\section{A GENERAL APPROACH TOWARD YOUTH AND CHILEAN POLITICS}

\begin{abstract}
This paper sets out to investigate some concepts developed by the sociologist Karl Mannheim on youth and generations, debating its current approach, then, takes a look at the sociological and historiographic production on gender and politics in Chile, ending with a conceptual proposal for addressing the problem of generations in connection with the cultures and political subjectivities.
\end{abstract}

KEY WORDS: MANNHEIM, POLITICAL SUBJECTIVITY, GENERATIONS 


\section{INTRODUCCIÓN}

EL SOCIÓLOGO HÚNGARO ALEMÁN Karl Mannheim escribió: «Para la continuación de la vida de nuestra sociedad, el recuerdo social es exactamente tan necesario como el olvido o la irrupción de nuevos actos... una especie que viviera eternamente tendría que aprender a olvidarse de sí misma, y compensar la falta de nuevas generaciones» (Mannheim, 1993). Con esto, el autor señalaba que la historia cobraba dinamismo en la medida que el olvido, la memoria y los diversos grados de conciencia en torno a las tradiciones, se manifestaban mediados por la emergencia de nuevas generaciones jóvenes. De hecho, agregaba Mannheim, es tal sucesión generacional la que «nos enseña a olvidar lo que ya no es útil, a pretender lo que todavía no se ha conquistado» (Mannheim, 1993). Dichas expresiones pueden resultar paradojales si se contrastan con la realidad actual de la militancia y la participación política en Chile, puesto que, si analizamos la profundidad de los cambios ocurridos en los modos de entender y practicar la política, tendríamos que concluir que en las últimas tres décadas se ha experimentado un cúmulo de cambios radicales, un verdadero torbellino de acontecer transformador que, no obstante, se acompaña de la percepción de que la renovación generacional es un proceso lento.

Partiendo por aquello que ha cambiado en la historia reciente de la vinculación juventud-política, consideramos relevantes los siguientes aspectos que sintetizan un proceso en curso.

a) Sentidos y cargas simbólicas de juventud y política en el paso de la democracia a la dictadura

Mientras los años 60 fueron de discursos renovadores e inclusivos de lo juvenil por parte de un centro y una izquierda política que apelaban a «la patria joven» y el «poder joven», ello se quebró cuando la dictadura en 1973, junto con prohibir los partidos y negar reconocimiento a las organizaciones de la sociedad civil, proyectó la imagen de un deber ser juvenil que desdeñaba la politización en aras de la unidad nacional (Muñoz 2003). Al mismo tiempo, si hasta 1973, la política atraía identitariamente a las nuevas generaciones socializadas en su valoración como ámbito decidor de la vida colectiva, en la segunda mitad de los setenta tal política no sólo fue satanizada por el régimen de Pinochet, sino que se le restó peso estructu- 
ral en la medida que la conducción del Estado —objetivo de la pugna política—, se consideró subsidiaria del mercado.

\section{b) Lo social y la política en el paso de la democracia a la dictadura}

Antes de 1973, y siguiendo una tendencia que venía desde los años treinta, el proceder de los actores sociales estaba conectado con la acción de las instancias formales de representación política, en otras palabras, relacionada con los partidos políticos. Tal imbricación entre partidos y organizaciones sociales (Garretón, 1994) se facilitaba por el hecho de que las demandas y discursos sectoriales contenían un horizonte político global, del mismo modo que los partidos tenían conexiones sociales afianzadas en orgánicas sectoriales, las que en algunos casos se manifestaban como militancia de masas. En tal contexto, los actores juveniles se transformaron en gran medida en dobles militantes tanto de organizaciones sociales como de partidos políticos, ocurriendo que las organizaciones sociales politizadas - «frentes sociales» en el lenguaje partidista - veían en los partidos políticos la posibilidad de unir las miradas sectoriales con las nacionales. Ello al mismo tiempo que los partidos de «masas» —o aquellos que sin ser de masas estaban involucrados en el activismo social-, entendían que los «frentes sociales» eran las instancias donde las políticas partidistas luchaban por la hegemonía desde las bases.

Con la dictadura militar, la represión encontró la resistencia de los movimientos sociales y partidos políticos que se reconstruyeron paralelamente desde la clásica figura del «doble militante social partidista», aunque esta vez, con eje en partidos políticos prohibidos y organizaciones sociales no reconocidas institucionalmente. Tal recomposición, con un fuerte componente de gestión cultural a fines de los años setenta, dio paso a coyunturas cada vez más confrontacionales durante los ochenta, en donde la lucha fue por ocupar los espacios públicos y ganar la representatividad de instituciones alternas al orden dictatorial, como fueron las federaciones estudiantiles. En resumen, mientras que antes de 1973 primaba una política en donde la interlocución de los referentes sociales juveniles con las instituciones estatales se desarrollaba tanto desde las instituciones de representatividad sectorial como desde los canales internos de la militancia partidista, durante la dictadura ocurrió que —no obstante se cerraron los canales de interlocución Estado-sociedad y se prohibieron los partidos políticos-, se rearticularon ámbitos de participación social y partidista que 
en tanto campos alternos a la institucionalidad del régimen, reprodujeron en parte lo que habían sido sus tradicionales lógicas de relación.

\section{c) La política y las organizaciones sociales representativas en el paso de la democracia a la dictadura}

Cuando en la dictadura se reconfiguró, lo que venía siendo desde la década 1930, una vinculación particularmente imbricada entre organizaciones sociales y partidos políticos, ocurrió que la cultura política altamente institucionalista de los chilenos encontró continuidad pese al régimen dictatorial. Fue así como la Federación de Estudiantes de la Universidad de Chile (FECH), reconstruida en 1984, aun cuando no tendría el más mínimo reconocimiento de la autoridad, nacía de un largo proceso de elaboración de estatutos que buscaban hacer de la federación un organismo único, normado y representativo de todo el alumnado. Algo similar pasó con las otras federaciones universitarias y con la federación de los estudiantes secundarios, FESES, que también junto con desarrollar esta institucionalización alterna a la dictadura, se reconstruían actualizando el viejo esquema de la doble militancia social partidista. Efectivamente, aquí los partidos políticos ilegales, pero con orgánicas de base reconstruidas, fueron determinantes en las demandas y lógicas de acción que se desarrollaban a nivel social, esto al tiempo que las listas a las elecciones de federación se acordaban en mesas partidarias bajo los ojos atentos de las direcciones políticas nacionales. De algún modo, se asumía por parte de los partidos, que tales experiencias eran también un valioso barómetro de aquella política nacional que, no estando presente en el parlamento, sí tenía en el mundo social un campo de reproducción.

\section{d) El eje dictadura/democracia en los años de la transición}

La repolitización de la sociedad en los años ochenta tuvo en el eje dictadura-democracia un catalizador de las conflictividades. Dicho eje fue más allá de la dicotomía autoritarismo —elecciones libres- e involucró toda la profunda transformación que la dictadura había materializado en las relaciones entre Estado, mercado y sociedad. No obstante, durante la transición no se abordó este carácter global de la tensión y los partidos políticos, más que atender a la conflictividad social, a revertir las modernizaciones autoritarias que dejaba el régimen, y a satisfacer expectativas de cambios estructurales (que en dé- 
cadas pasadas coparon buena parte de sus preocupaciones), tendieron a eludir los efectos disruptivos de tal conflictividad y promesas de cambio, orientándose a lograr acuerdos parlamentarios sobre la base de la aceptación de la «obra gruesa» del modelo político y económico vigente, heredado de la dictadura. Sin duda, los llamados «enclaves autoritarios»; es decir, existencia de senadores designados, inamovilidad de los jefes de las fuerzas armadas, atribuciones y carácter del Consejo de Seguridad Nacional, colaboraron con esta tendencia en que el imperativo pragmático de consenso se impuso a fuerza de una tecnificación y desvinculación social de la política. Entre los efectos inmediatos de esta situación, ocurrió que la reconfiguración de los partidos dentro de un sistema legal, el retorno de los mecanismos electorales de participación y el reconocimiento de las instancias representativas del mundo social, se vivieron en paralelo con una crisis de las conexiones «de masas» de muchos partidos y un declinar del interés ciudadano por participar en los procesos electorales. En síntesis, se perdía el carácter totalizador que las ideologías utópicas de la modernidad le habían conferido a la política, esto en la medida que el creciente poder definitorio del mercado contrastaba con el vaciamiento de contenidos en las disputas programáticas por la conducción del Estado.

\section{e) Sentidos y cargas simbólicas de juventud y política en la transición a la democracia}

Un modismo juvenil recurrente en los años noventa fue «no estoy ni ahí», expresión traducible como «no me interesa», que parecía calzar con el creciente desinterés por la participación política y electoral, así como con la ausencia de debate político en la cotidianidad. Tal desinterés era particularmente visible en los jóvenes, que eran quienes no estaban acudiendo a inscribirse en los registros electorales, en circunstancias que los mayores ya lo habían hecho durante la coyuntura plebiscitaria de 1988. Se popularizó entonces una imagen que representaba a los jóvenes como expresión extrema de apoliticismo, y se tendió a asimilar lo juvenil a la apatía que entonces simbolizaba el joven tenista Marcelo Ríos, figura pública que parecía no motivarse por nada que no fuera su propia persona en una cancha de tenis. Sin embargo, no todos vieron en el diagnosticado apoliticismo un problema, incluso algunos lo valoraron positivamente atendiendo a que cierto desinterés en la política podría indicar que el país funcionaba sin mayores conflictos. Pero independientemente de lo anterior, lo cierto es que la 
situación era más compleja que un repentino apoliticismo en los jóvenes, de hecho, todavía más compleja que una desafección generalizada de los ciudadanos con respecto a la política. Lo que estaba en curso era que no sólo se vaciaba de política lo juvenil y lo social, sino que la propia política se vaciaba de conflictos y de miradas globales. En este sentido, hubo un discurso y una práctica que pretendieron desconectar a la política de la sociedad, ello al plantearse una separación entre los grandes y complejos temas "políticos» —las relaciones entre Estado, mercado y sociedad, abarcando en esto los cuestionamientos a la constitución y al modelo económico-, y lo que se suponía más simple, concreto y de efecto inmediato y palpable en lo «social» como «hacer cosas para la gente», preocuparse de «los reales problemas de la gente». Quienes extremaron esta mirada, promovieron discursos que declaraban a la política como debate esencialmente alejado de los ciudadanos, esto al punto de levantar candidatos presidenciales que se declaraban «no políticos» y sí «hacedores de cosas», como fue el caso de Joaquín Lavín en 1999 (Moulián, 2004). No obstante, esta realidad ha ido cambiando. Hoy los contenidos simbólicos asociados a política y juventud se encuentran en plena revisión y pugna. Una creciente presencia pública de movimientos ciudadanos juveniles como el estudiantil (movilizaciones 2006-2011), hacen presente día a día su descontento con los marcos institucionales de la política, al tiempo que se asumen como legítimamente "políticos» desde lo social, abordando tópicos como reformas tributarias, nacionalización de recursos naturales y una nueva constitución. Con ello, el apoliticismo ha dejado de ser presentado como sinónimo de juventud, pero lo pendiente sigue siendo el modo en que se comprende y proyecta la conexión entre sociedad y política.

\section{f) Lo social y la política en la transición a la democracia}

En la cotidianidad transicional, los partidos políticos cambiaron su estructura desde masivas agrupaciones de «dobles militantes» socialespolíticos, a orgánicas reducidas aunque profesionalizadas desde su inserción en esferas de administración de gobierno nacional o local. Entonces, pareció acentuarse la diferencia entre «la política» entendida como campo estructurado formalmente a nivel institucional y de gobierno, en donde se establecen las relaciones de poder conectadas con la conducción general de la sociedad (representatividad electoral y partidos políticos); y una dimensión de «lo político» vinculada al modo cotidiano en que los diversos sujetos asumen la construcción de la realidad social 
deseada, como instancias de sociabilidad, organizaciones civiles, movimiento ciudadanos (Garretón, 2007) y que contiene las conflictividades o antagonismos de fundamento social e identitario (Mouffe, 2007). Es decir, la institucionalidad de «la política» pareció cada vez más desconectada de aquello que la nutre y legitima en un orden democrático: su capacidad de ser permeada por «lo político» presente en las proyecciones e intereses que conflictivamente habitan lo social.

\section{g) La política y las organizaciones sociales representativas en la transición a la democracia}

Durante la transición política, la decepción primó en buena parte de las fuerzas opositoras que presenciaron la mantención de la constitución autoritaria y del modelo económico. Ello generó la desarticulación de gran parte de las redes organizadas en los territorios y centros de estudio. A partir de entonces, las nuevas organizaciones se reconstruyeron ya no al antiguo estilo de la doble militancia social partidista, sino desde referencias diversas, varias de ellas autónomas respecto a los partidos. Estos últimos, se reconfiguraron institucionalmente, pero perdieron presencia local. En los territorios, como ocurriera a fines de los años 70, proliferaron los agrupamientos en torno a motivaciones artístico-culturales. En los estudiantes, las federaciones universitarias a principios de los noventa entraron en crisis, pero luego se rearticularon y llegaron a ser dirigidas por miembros de antiguas o nuevas agrupaciones de identidad política. En el caso específico de la Universidad de Chile, la FECH fue liderada por cuadros del Partido Comunista (PC), a mediados de la década del 90 y luego en 2010-2011.

Por su parte, los secundarios no reconstruyeron federaciones sino que vocerías vinculadas a asambleas de colegios. Los partidos políticos también estuvieron presentes en estas últimas experiencias, aun cuando sin la masividad que tuvieron durante la dictadura y coexistiendo con un sinnúmero de pequeñas agrupaciones de identidad sociopolítica.

Como advertimos al inicio, la particularidad de las mencionadas transformaciones es que no se acompañaron de una notoria sucesión generacional entendida como emergencia juvenil de votantes, liderazgos y partícipes activos del quehacer político militante. Sobre los votantes, ya van veinte años de un diagnosticado envejecimiento del padrón electoral. Sobre la emergencia de cuadros juveniles, tenemos que en el centro y la izquierda política el problema del estancamiento de la sucesión generacional ha sido constante desde que la generación 
que lideró la transición fue la que ya ocupaba lugares de protagonismo en 1973, tendencia que se ha matizado tímidamente en los últimos años. En la derecha, el problema ha sido menor (Joignant y Navia, 2003; Insunza y Ortega, 2007) sobre todo en la Unión Demócrata Independiente, UDI, razón por la que su presidente Juan Antonio Coloma, citando al conocido cantante Ricardo Arjona llegó a hablar de la «amalgama perfecta entre experiencia y juventud» que caracterizaba a la tienda gremialista (La Tercera, 26-05-2010). De todos modos, los signos de distanciamiento entre jóvenes y militancia son claros para buena parte del espectro político y desde hace ya dos décadas.

Nos parece que este contexto debería estimular una revisión de la perspectiva teórica de las generaciones, o como lo definiera Mannheim, del problema sociológico de las generaciones y su conexión con las culturas y subjetividades políticas en Chile. Como aporte a tal debate, el presente texto se plantea exponer algunos conceptos desarrollados por el sociólogo Karl Mannheim sobre juventud y generaciones, argumentando la actualidad de sus planteamientos, para luego, dar una mirada a la producción sociológica e historiográfica sobre generaciones y política en Chile, finalizando con una propuesta conceptual para el abordaje de los tópicos señalados.

\section{GENERACIONES, JUVENTUD Y POLÍTICA EN KARL MANNHEIM}

¿Qué relación existe entre el hecho constante de la renovación biológica de la especie humana y la construcción histórica de las sociedades? Esta es la pregunta básica que se ha intentado abordar desde el concepto de generación. No obstante, las respuestas propuestas han sido diversas y han variado según la preponderancia otorgada a cada uno de los dos elementos relacionados en la propia pregunta. Por un lado, el hecho biológico y vital (la gente nace, vive determinada cantidad de años y muere, sintiendo y asumiendo de modo distinto la vida según su edad) y por otro, el acontecer histórico social (el modo en que los humanos organizan su coexistencia, producen, distribuyen lo producido y disputan poder).

Ortega y Gasset, por ejemplo, sintetizó dos tradiciones europeas referidas a la teoría de las generaciones: la teoría positivista francesa de Comte y la teoría histórico-romántica alemana de Dhilthey, entendiendo lo generacional como un factor definido biológica y vitalmente, que determina lo sociohistórico (Ortega, 1994-1956). Según su idea, el dato biológico de la edad y cierto límite relativa- 
mente fijable de la duración máxima de la vida, llevarían a concluir tres cuestiones fundamentales que resultan una síntesis de los pensamientos positivista y romántico. Primero, que existirían duraciones universales de una generación histórica, y ésta sumaría treinta años: quince años de «formación» y quince de «predominio» en un tramo vital que va entre los 30 y los 60 años del ser humano. En segundo lugar, que habría atributos esenciales de las edades, en donde la actoría histórica real vendría después de la juventud (esta última, periodo que va entre los 15 y 30, edad en que no se crean nuevas ideas ni proponen nuevos mundos, pues los sujetos están ensimismados en su egoísmo) y estaría compuesta por un momento de intensa creación y pugna entre los 30 y 45 años, y aquella edad entre los 45 y 60 en donde las ideas propias constituyen lo aceptado y gobiernan el mundo, después de lo cual el sujeto sale de la vida pública. En tercer lugar, se establece la existencia de un ritmo predeterminado de la historia y marcado por zonas de fechas de quince años: «la tonalidad histórica varía cada quince años» (Ortega, 1994), lo que serviría de fundamento a un «método generacional» que observa con particular atención hitos biográficos en personajes considerados claves («epónimos») para sus respectivas generaciones y áreas de acción histórica. De tal modo, el año en que determinados personajes claves (Ortega ejemplifica con Descartes en la filosofía) cumplen sus treinta años de vida, se valora como un hito a partir del que es posible establecer «zonas de fechas» y deslindes generacionales (es así como la zona de fechas existente entre el cumpleaños número 30 de Descartes y el de Hobbes, es para Ortega un dato relevante en lo que se refiere a definir si tales personajes pertenecen o no a la misma generación en la historia del pensamiento).

Por su parte, Karl Mannheim en su texto «El problema de las generaciones» de 1928, se deslinda de las tradiciones positivista e histórico romántica, lo que lo diferencia de su contemporáneo Ortega y Gasset. En el marco de su crítica, este autor destaca lo histórico-social como eje analítico del problema de las generaciones, no obstante, reconoce que el fenómeno generacional se fundamenta en el hecho biológico del nacimiento y la muerte. En este último sentido aclara:

Estar fundamentado en algo no llega a significar ser deducible de, estar contenido en, ese algo. Un fenómeno que se fundamenta en otro no puede darse ciertamente sin él, pero contiene en sí, en contraposición con el 
fenómeno que lo fundamenta, un sobreañadido cualitativamente propio y no deducible de aquel. Si el «ser con otro» de la sociedad de los hombres no se diera, si no se diera una historia que se apoya en continuidades específicas de cierta clase, no nos enfrentaríamos entonces, con las formas de conexión generacional que se apoyan en el fenómeno de la posición, sino tan sólo con el nacimiento, el envejecimiento y la muerte (Mannheim, 1993:209).

De tal modo, Mannheim entiende que aquel fenómeno fundamentado biológicamente -que es la generación-, se vive histórica y socialmente, sugiriendo con ello interrogantes que desbordan el dato biológico. Por lo anterior, su mirada apuesta por definir lo generacional como un «problema sociológico», restándole el carácter de llave maestra para la comprensión de una historia enmarcable en un ritmo predeterminado, pero valorando en cambio su importancia como perspectiva que conecta las edades y sucesiones biológicas con la conflictiva construcción de cultura y órdenes sociales en la historia.

Desde su enfoque, las generaciones son referencias de una «posición» o «localización» histórico-social, la que otorga similitudes a quienes caben en ella. No obstante, lo generacional abarcaba también procesos históricos de identificación de los sujetos con las ideas en torno al cambio y conservación de las sociedades. De tal modo, en un sentido de mayor especifidad, está lo que denominó «conexión generacional» que da cuenta de la participación en el devenir de la unidad histórico social que define la posición, pues hay tal conexión siempre que se produce un vínculo entre los individuos de una posición generacional y los contenidos presentes en «los terrenos de lo que se está desestabilizando y de lo que está en renovación» (Mannheim, 1993), vínculo que supone el involucramiento de los coetáneos con «aquellas corrientes sociales y espirituales que constituían precisamente el momento histórico respectivo» (Mannheim, 1993). Pero tales corrientes socio-espirituales no se definirían en una misma interpretación de realidad y apuesta histórica, sino que, estando en una misma conexión generacional, representan ideas diversas, incluso opuestas. Es decir, «unidades generacionales» que señalan proyecciones y sentidos específicos que se debaten al interior de una misma problemática de renovación histórica (Mannheim, 1993). Es así como se expone lo generacional como una problemática compleja y mediante una conceptualización multidimensional que lejos de cerrar el concepto y limitarlo a los aspectos histórico-estructurales de una «posición» (definida como 
independiente de la conciencia, al modo de «la clase» dice Mannheim), lo abren a lo subjetivo e identitario, posibilitando el entender la generación también como una construcción cultural.

En este último sentido, un elemento clave de la perspectiva de Mannheim se desarrolla en torno a cómo entiende que opera la estructuración de la conciencia en jóvenes y adultos. Mediante el concepto de «estratificación de la vivencia» sostiene que lo vivido por los jóvenes constituye «primeras impresiones» que se configuran como «imagen natural del mundo», razón por la que todas las experiencias posteriores o tardías, se verían orientadas de acuerdo a aquella primera impresión, ya fuera como afirmación de ese estrato o como negación de aquel. Se produce, a decir del sociólogo alemán, una «dialéctica de la vivencia», pues lo que se vive no se va acumulando sino que se enfrenta en los sentidos ya señalados. «El predominio de las primeras impresiones permanece vivo y determinante, aun cuando todo el decurso sucesivo de la vida no tenga que ser otro que el de una negación y una descomposición de la «imagen natural del mundo» recibida en la juventud» (Mannheim, 1993). En el suceder de las generaciones, al cambiar el mundo, van cambiando los contextos de las vivencias primarias y sus referencias orientadoras. Por tanto, si se asume que cada generación vivencia contextos que contienen elementos a los que se enfrenta en tanto antagonismos, ocurre que en el caso de dos generaciones que se suceden una a la otra, los antagonismos son distintos pues los mundos exteriores (la realidad socio histórica) e interiores (la conciencia) han cambiado, de modo que mientras los adultos se enfrentan continuamente a algo que permanece en ellos (plasmado en su conciencia como exterioridad vivida), los jóvenes tienen como referencia básica un mundo diferente al de los adultos, y en ellos, habrán desaparecido elementos que los mayores conservan dentro de sí. En este proceso, la socialización en la cultura se desarrolla inconsciente y conscientemente. Aquellos contenidos y disposiciones que no han sido cuestionados socialmente, se transmiten de modo inconsciente, mientras que lo que está en cuestión, aquello que en algún momento de la historia se ha vuelto «problemático y reflexivo» se transmite de modo consciente. Son los jóvenes, quienes desde los 17 años aproximadamente (dice Mannheim, «a menudo antes, frecuentemente después» de tal edad, negando con esto un criterio matemático fijo y propio del positivismo en torno a lo etario) comienzan a vivenciar el presente en su dimensión problemática, dando cuenta del mencionado momento clave de la estratificación de la vivencia. Sólo entonces, durante la juventud, dice 
Mannheim: «se constituirían aquellos estratos de los contenidos de la conciencia y aquellas disposiciones que - debido a la nueva posición histórico social- han pasado a ser problemáticos y que, por eso, se han hecho conscientes; solo entonces se está verdaderamente «presente»... El hecho que la juventud «esté presente» significa, incluso, vivenciar como antítesis primaria lo que se ha concebido en una situación de desestabilización...» (Mannheim, 1993). Para el autor, esta vivencia de los contenidos problemáticos en un período juvenil marcado por su carácter primario en la estratificación de la conciencia, determina las diferencias e interrelaciones generacionales. Esto último lo ejemplifica en la educación, en donde el maestro conserva dentro de sí un eje de orientación problemático de la vida distinto al del discípulo joven. ¿Una tensión insuperable? No dice Mannheim, pues existe la «tendencia retroactiva» en la transmisión de cultura, lo que se expresa en que «no sólo educa el maestro al discípulo, sino que el discípulo también al maestro. Las generaciones están en incesante interacción» (Mannheim, 1993:220). La dialéctica de la estratificación de la vivencia es, por tanto, el sostén de una vinculación también dialéctica y relacional de las generaciones.

Desde estos conceptos, se relevan dos dimensiones que tanto en Ortega como en las tradiciones histórica romántica y positivista no tenían la centralidad que les otorga Mannheim. En primer término, el autor alemán sostiene que las corrientes de pensamiento vinculadas a lo que se conserva y cambia en las sociedades, constituyen un campo en donde se articula lo generacional, de modo que la política y las identidades involucradas en ella, cobran particular notoriedad en sus análisis. Mientras Ortega considera los fenómenos políticos como subordinados a las ideas, la moral y la ética (que a su vez serían consecuencias y especificaciones de la sensibilidad vital), Mannheim otorga a las disputas político ideológicas un valor integral, en el sentido que las vincula tanto a las posiciones de clase como al pensamiento, el sentimiento y la vivencia, de modo que las tradiciones y cambios que se susciten en tales esferas dan cuenta de un ámbito "socioespiritual» a partir del cual se articulan conexiones y unidades generacionales. Por lo mismo, los ejemplos a los que el autor alemán recurre para explicar sus conceptos, son de carácter político: las revoluciones, los liberalismos y los conservadurismos, las pugnas socio históricas en que memoria, olvido, conservación y transformación han estado presentes como mutación cultural mediada por la sucesión de las generaciones. En un segundo término, es clara la distinción entre los nexos 
que Mannheim y Ortega perciben entre juventud y generaciones. Como ya se dijo, el filósofo español da características esenciales, permanentes y universales a la juventud, en el sentido de que ella constituiría una etapa «egoísta» previa a cualquier reflexión e interés orientado hacia lo colectivo, lo que refrenda con la idea de que la verdadera actoría generacional ocurre luego de la juventud, durante las dos etapas maduras de «creación» (30 a 45 años) y "predominio» (45 a 60 años). Para Mannheim, en cambio, la juventud no sería una realidad de características universales y permanentes, pues aunque reconoce en la pubertad un factor biológico de la especie humana, considera que es en los tiempos modernos en donde esa pubertad se vivencia como experiencia de socialización en que se problematiza el orden social: «El hecho decisivo respecto a la edad de la pubertad para nuestro punto de vista es que la juventud entra en esa edad en la vida pública y que es entonces cuando en la sociedad moderna tiene que enfrentarse por vez primera con el caos de las valoraciones antagonistas» (Mannheim, 2005:53). De este modo, el antagonismo propio del debate político entendido como las pugnas sobre lo que se conserva y cambia en sociedad, es percibido primariamente en la socialización que se efectúa durante la juventud (de ahí la importancia de lo juvenil en la estratificación de la vivencia), no obstante, ello no sería una realidad común en toda época y contexto, sino que una característica particularmente acentuada en el mundo moderno. Paralelamente, Mannheim otorga protagonismo actoral a los jóvenes no sólo por este lugar primario de la vivencia juvenil en la construcción dialéctica de la conciencia de lo vivido, sino también porque, a su juicio, la juventud representa el ingreso de una nueva generación que revitaliza lo social dada su particular disposición al cambio. Esta última se debería a que su aún precaria inserción en el orden sistémico la sitúa en un lugar particularmente sensible a orientaciones reformistas, aunque ellas no contengan valor esencial en tanto "progresivas», «reaccionarias», «democráticas» 0 «autoritarias» (Mannheim, 2005:53).

La juventud no es progresiva ni reaccionaria por naturaleza, sino una potencialidad dispuesta siempre a toda renovación... El factor especial que hace del adolescente uno de los elementos más importantes en toda renovación de la sociedad es el hecho de que ese adolescente no acepte el orden social establecido como algo dado por supuesto y que no tenga intereses adquiridos ni en su orden espiritual ni en lo económico 
(Mannheim, 2005:55).

El período en el que Mannheim hizo los planteamientos acá comentados, fue de vertiginosos cambios, desde fines de la década del 20 hasta plena segunda guerra mundial en los años 40. Es en su texto de 1943 «El problema de la juventud en la sociedad moderna» en donde el sociólogo toma posiciones políticas en torno al contexto de guerra y el rol de los jóvenes en su contemporaneidad. Escrito en Inglaterra, es a los ingleses a quienes se dirige directamente, les critica su sistema tradicional de educación y un orden cultural que, a su juicio, marginaba el ímpetu juvenil y lo restringía en pro del conservadurismo, mientras el nazismo, por su parte, habría apelado justamente a la juventud para proponer su cambio, aunque tal incorporación de los jóvenes no fuese en función de la participación sino de la obediencia fanática en un marco totalitario. Para Mannheim, la no comprensión e incorporación del protagonismo juvenil sería una desventaja cultural de Inglaterra frente a su enemigo, una traba que de no ser solucionada le impediría «ganar la guerra y la paz» en un contexto en que la guerra era también entre ideas y sistemas sociales. El autor propone, entonces, tener una política que incorpore la actoría de las nuevas generaciones «dar a los jóvenes la oportunidad de que puedan llegar a ser colaboradores eficaces en un movimiento amplio que persigue la solución de los problemas corrientes y la reconstrucción social» (Mannheim, 2005:69). Es aquí donde los contenidos de la obra de Mannheim parecen encontrar una síntesis: por un lado el problema de las generaciones, por otro el problema de la juventud moderna, y como vértice común, la preocupación por la política y la democracia en tanto espacios en donde se construye conflictivamente el orden social. Para él, tal política y democracia, a fin de mantenerse vitales e inclusivas, debían conectarse con lo que la pluralidad juvenil construía en la continua renovación de las sociedades. A su entender, aunque tal incorporación de los jóvenes no implicaba ninguna esencia de progreso, sí era un deber ineludible para una sociedad que manifestara la intención de

1 Si bien es discutible en qué medida el adolescente tiene o no intereses «adquiridos» en el orden social (económico espiritual), pues las posiciones median claramente en los espacios y las subjetividades de las instancias de «moratoria social» juvenil, también es cierto que hay consenso en los estudios en el sentido de que la juventud marca un período de tensión existencial en donde aún no está plenamente configurado el estatus y la posición que el joven adquirirá como adulto. 
pensarse y construirse a sí misma.

\section{LAS GENERACIONES Y EL ESTUDIO DE LAS SUBJETIVIDADES POLÍTICAS EN CHILE}

Lo generacional ha sido un tópico presente en estudios histórico sociales en Chile, pero ello no ha implicado una revisión teórico conceptual que dialogue con las diversas tradiciones y, a partir de ello, proponga miradas nuevas. Por lo anterior, podemos diagnosticar la ausencia de una perspectiva, enfoque o universo problematizador de lo generacional, que nos remita a determinados conceptos, autores y posiciones en pugna. Pareciera, al contrario, que muchos análisis partieran de cero o de miradas parciales, lo que dificulta el avance en la construcción de conocimiento sobre el problema de las generaciones y su vinculación con los debates contemporáneos.

Entre los abordajes de lo generacional se encuentra una reciente historiografía que ha estudiado movimientos sociopolíticos particularmente cruzados por lo juvenil. Fue Gabriel Salazar quien llevó a la juventud a una historia general de Chile y lo hizo mediante el concepto de «generaciones» (Salazar y Pinto, 2002). Si bien este historiador no se detiene en teorizar respecto a lo generacional o en debatir con la tradición de los autores clásicos, sí expone un análisis que involucra una determinada comprensión de la problemática. Por ejemplo, en lo que se refiere al análisis de "generaciones políticas con orientación transformadora», compara el tránsito histórico de algunas de ellas: la «generación de 1848», que luego de la fugaz existencia de la «Sociedad de la Igualdad», ${ }^{2}$ instaló desde los años 60 del siglo XIX un proyecto liberal de cambio estrictamente político institucional laico, abandonando aspectos de transformación democrático social que en algún momento planteó; las generaciones rebeldes de 1920 y 1930 que se resistieron primero al parlamentarismo y luego al autoritarismo, y que como generaciones adultas impulsaron el proyecto democrático desarrollista desde 1938; la paradigmática generación revolucionaria de 1968 y la posterior generación movilizada contra la dictadura en

2 La «Sociedad de la Igualdad» (1850-1851) fue un agrupamiento político impulsado por jóvenes liberales influenciados por las revueltas europeas de 1848. 
los años 80. En el análisis, es central la articulación de identidad que opera desde la interrelación: aquellos «encuentros» en que cada generación juvenil se conforma a sí misma desde reacciones a las construcciones, lógicas y posiciones sustentadas por las generaciones previas. No obstante, las generaciones no serían estatuas de época y cambiarían junto con los contextos y los roles que van adquiriendo los sujetos, de modo que será recurrente que rupturismos de juventud devengan en actitudes más conservadoras respecto a los órdenes sistémicos.

Lo mismo que la generación juvenil de 1848 (que tras su retorno prodigo tomó a su cargo el estado y el mercado y realizó paso a paso la desintegración del autoritarismo portaliano y la instalación del liberalismo parlamentarista sin una reforma estructural de la constitución de 1833), la generación del 38, cuando tomó a su cargo el Estado y el Mercado, intentó desintegrar el liberalismo recibido en herencia e instalar a cambio una democracia social, sin una reforma estructural de la constitución de 1925. [...] La del 48 había encontrado, desde 1906, en el fondo de su crisis, una generación juvenil crítica y revolucionaria, la del año 20. La del 38, por su parte, en el fondo de su crisis, se encontró con otra juventud crítica y revolucionaria, la de 1968 (Salazar y Pinto, 2002:129).

Es importante hacer notar que en este análisis, lo generacional navega por diversas duraciones históricas, lo que queda claro en la cita anterior, en donde lo que el autor analiza es la vivencia de procesos que trascienden una fecha o coyuntura, no obstante, ésta última sirve para nombrar las tendencias que se asocian a tales procesos, como el identificar 1848 con la generación que consolida un liberalismo y una forma de acción política que llega a su crisis a principios del siglo Xx; o identificar en 1906 (año de la fundación de la FECH) el surgimiento de una tendencia que encuentra su referente paradigmático catorce años después, en 1920. Por eso, el año que analíticamente sirve para nombrar una generación, en este caso, no implica necesariamente que sólo sean asumidos como parte de ella los que vivenciaron como jóvenes tal coyuntura, sino que se pone acento en la vivencia de aquellas tendencias de mayor longitud histórica que el historiador expone como claves de análisis. Esto último, nos indica que en la delimitación de una generación influye bastante el abordaje temporal (o las diversas duraciones históricas) de la mirada del observador. De este modo, Salazar aplica un concepto flexible, que en el análisis específico de «generaciones políticas», da potentes resultados en torno a los vínculos entre construcciones identitarias y relaciones intergeneracionales. 
Por cierto, el historiador pone de manifiesto su conocido posicionamiento sobre lo social, la ciudadanía, el Estado y la legitimidad de éste último (Salazar y Pinto, 1999), lo que es determinante en su tratamiento del problema generacional. En la obra de Salazar, el suceder de las generaciones políticas se presenta como expresión procesual de la tensión histórica de fondo entre legitimidad e ilegitimidad en la construcción de Estado, sugiriéndose que el rupturismo juvenil de algunas generaciones con orientación transformadora, marcaría constantes intentos de unir acción política y legitimidad social. En esto se deja entrever cierto continuo cíclico en donde un proyecto legitimador y sociocrático vuelve una y otra vez a intentar materializarse, lo que sería atravesado por el fenómeno generacional. Desde este enfoque, abundan los ejemplos históricos de «rupturas juveniles» que desembocan, como práctica adulta, en «retornos pródigos» a la política institucional enmarcada en un orden constitucional ilegítimo. En función de este hilo argumentativo, el autor escoge y delimita los núcleos generacionales que aborda, relevando aquellas determinadas corrientes que le permiten asociar la «orientación transformadora» de actores juveniles politizados, con lo que contextualmente representaría, a su juicio, un mayor quiebre con una construcción de Estado históricamente no legítima. ${ }^{3}$ Independientemente de si se coincida o no con Salazar en estas definiciones socio políticas que enmarcan su análisis (que, por lo demás, han sido tema de un antiguo y siempre vigente debate sobre las concepciones y valoraciones de la política, lo político y lo social) el abordaje que ha hecho el historiador nos aporta con dos cuestiones fundamentales, por un lado, entender la generación como una construcción dinámica, relacional e identitaria, y por otro, asumir que el enfoque del analista será determinante en las duraciones, el carácter y los relevamientos que se establezcan respecto a las generaciones.

Una mirada que sin abandonar el foco en los sujetos que caracteriza la historia social, releva y reivindica el estudio de la especificidad del campo político en sus vínculos sociales e institucionales, es la que ha aparecido recientemente en una serie de estudios que exploran aquellos procesos subjetivos y culturales que conforman a movimien-

3 Para el caso del «68», se detiene mucho en las juventudes políticas radicalizadas y rupturistas con el orden constitucional, como el MIR y en parte el MAPU, no así, por ejemplo, en los jóvenes comunistas, aun cuando el protagonismo de estos últimos es claro en los movimientos juveniles. 
tos y partidos chilenos en las últimas décadas. Es desde tal perspectiva que autores como Verónica Valdivia, Cristina Moyano, Rolando Álvarez y Julio Pinto, han desarrollado una línea de investigación en historia política contemporánea que por momentos se conecta con la problemática de las generaciones. Donde esto último aparece de modo más nítido, es en el estudio de aquellos conglomerados de militancia que tienen un particular sello generacional como es la UDI en el caso de la obra de Verónica Valdivia (Valdivia, 2006-2008) y el MAPU en los escritos de Cristina Moyano (Moyano, 2010-2011). En la obra de Valdivia, lo generacional aparece como marco socio histórico que sella las motivaciones e identidades de aquel movimiento que desde sus orígenes como gremialismo estudiantil, hasta su consolidación política en dictadura, logró revitalizar a la derecha, materializar un proyecto constitucional y conducir la revolución neo liberal en Chile. Los testimonios analizados del propio líder gremialista-UDI, Jaime Guzmán, sobre sus motivaciones históricas, son claves para presentar la tesis de un movimiento que se pensó y construyó como respuesta a la profunda derrota de la derecha en lo social y la inversamente proporcional fortaleza de la izquierda y el centro político en ese mismo campo durante los años sesenta. La UDI aparece, entonces, como fruto del aprendizaje de una generación que articuló un imaginario de sí misma, imaginario mediante el que interpretó su historia y formuló su proyecto: una derecha que aun cuando entendiera la política como práctica de elite, concibiera una conexión social que la dotara de apoyo popular y rompiera con el correlato de clase de la cultura de los tres tercios.

Por su parte, Cristina Moyano en su obra sobre el MAPU, define a tal partido como «generacional», ${ }^{4}$ de vida corta e intensa, pero de prolongada sobrevida como cultura política ${ }^{5}$ anclada en las redes, prácticas e influencias de sus cuadros. En este caso, una metodología en base a testimonios le permite a la historiadora desarrollar una notable

4 Hay homogeneidad generacional pues tras el quiebre con la Democracia Cristiana que da origen al MAPU, los cuadros juveniles permanecen y toman la conducción del nuevo partido, mientras los ex DC de más edad, derivan en 1971 a la Izquierda Cristiana (IC).

5 Moyano describe la cultura política de un partido como un concepto que comprende: «...la manera de construir discursos políticos, la formación de auto y heteroimágenes, las prácticas políticas, las formas de organización y de lucha, las redes sociales y los modos de expresar discursivamente la experiencia de vida» (Moyano, 2010:37-38). 
cercanía con la subjetividad militante y el modo en que la construcción de identidad generacional determina los contenidos de la cultura política mapucista. Una de las conclusiones fundamentales es que tal cultura estaría marcada por un intenso periodo de socialización juvenil entre 1968 y 1973, en donde los años de fundación y quiebre con la Democracia Cristiana (DC), dan paso a definiciones y divisiones mientras se ocupan cargos de poder durante el gobierno de la Unidad Popular Up, esto hasta que el golpe militar fractura radicalmente la estructura y vida militante. La continuidad inmediata de esta intensa socialización, fueron las lecturas de la derrota y las perspectivas de futuro político que la generación MAPU desarrolló desde la renovación socialista, experiencia que abarcó la reconfiguración identitaria de lógicas, horizontes y prácticas militantes a partir de esta doble mirada que conectaba las interpretaciones del pasado reciente (la socialización política vivida en la juventud) con las perspectivas de futuro (un proyecto de transición a la democracia). Hacia 1990 tales lecturas e imaginarios histórico generacionales fueron centrales en la materialización de la transición política, y ocurrió que la generación MAPU que ya era protagonista en 1973, volvió a serlo, aunque el MAPU hubiese dejado de existir en 1989. Entonces, el pasado juvenil demócrata cristiano de los ex mapucistas fue vital para facilitar diálogos entre la izquierda y la DC al interior de la «Concertación» gobernante, mientras que el origen socio económico de elite que los caracterizó, otorgó notables redes e influencias tanto políticas como empresariales. De tal modo, la generación, o más bien el partido de impronta generacional que sería el MAPU, aparece como comunidad política que, trascendiendo al partido mismo, construyó un imaginario interpretativo de la historia común, articulando y justificando con ello, prácticas, lógicas y sentidos políticos culturales.

Otro autor que trata lo generacional vinculado a la historia política es Yanko González, quien busca dar cuenta del modo en que se generan identidades actorales desde los vertiginosos contextos que cimientan las culturas juveniles en la primera mitad del siglo XX (González, 2003). González enlaza la perspectiva de los estudios antropológicos de juventud (Feixa) con las miradas sociológicas (Mannheim y Bourdieu), con el fin de dar luces sobre la primera mitad del siglo XX, momento en que, a su juicio, se consolida el cruce entre la juventud como fenómeno cultural y socio estructural, con un protagonismo político juvenil que será prolífico en la producción de imaginarios identitarios de juventud y generación. El autor se detiene en un 
tema poco conocido (o invisibilizado) como el del «nacismo» chileno (de ese modo, con «c») en la década de 1930. Desde tal eje, aborda un contexto en que están en ebullición una serie de propuestas particularmente marcadas por lo juvenil-estudiantil, propuestas que cuestionaban el liberalismo en crisis (los socialismos, la juventud falangista, el obrerismo del grupo estudiantil «avance») y daban inicio a modos de comprender lo político y lo social que se proyectarán en buena parte del siglo XX. En definitiva, la propuesta pretende unir una mirada histórico generacional con una cultural antropológica, buscando la comprensión tanto de los procesos socio políticos como de la construcción social-simbólica de lo etario.

Por parte de las ciencias sociales, se han publicado en Chile análisis que exponen las tradiciones en torno al concepto «generación» como insumo para los estudios de juventud (Ghiardo, 2004; Leccardi y Feixa, 2011). Al mismo tiempo, y en el ámbito de los estudios, han destacado investigaciones sobre participación política y electoral desde un enfoque generacional. Esto último, tuvo su inicio cuando al comienzo de la posdictadura, Rodrigo Baño y Enzo Faletto propusieron comparar comportamientos de apoliticismo por medio de análisis estadísticos realizados entre mediados de la década de 1960 y el inicio de 1990, formulando, para ello, tramos etarios con cortes generacionales según contextos de socialización política vivenciados durante la juventud (se estableció como referencia la edad de 19 años pues se estimó que entonces estarían asentadas las bases generales de la socialización política) (Baño y Faletto, 1992). Se propusieron, en dicho estudio, tres generaciones a analizar, la primera, aquella que se socializó políticamente durante la democracia previa a 1958, la segunda, que lo hizo en el periodo de alta conflictividad democrática entre 1958 y 1973, y la tercera, cuya socialización política se vivió durante la dictadura entre 1973 y 1989. Mediante estas unidades de análisis, se observaron los cambios manifestados por los sujetos de cada tramo y en cada contexto de medición, de modo que la proyección histórica y el carácter dinámico de los análisis, desbordaban los clásicos tratamientos realizados a partir de los tramos etarios. Tal mirada fue seguida posteriormente por otros autores que fueron sumando el material estadístico a comparar (Madrid, 2005; Toro, 2008). ${ }^{6}$ Sin duda, estos traba-

6 En una línea diferente, el sociólogo y jurista Edmundo Fuenzalida ha optado por el método generacional orteguiano en el análisis de los cambios en la cultura política. Este autor propone tramos generacionales de 
jos nutrieron los estudios de participación política con una perspectiva histórica que permitió superar una serie de estigmas y reduccionismos asociados a nociones universalistas de la edad, como era el hecho de atribuir cierta politicidad o apoliticismo esencial a determinada condición etaria. Por otro lado, tales abordajes entendieron lo generacional como problemática a vincular con el conjunto de factores socio históricos, lo que en los hechos implicó relevar el análisis de las distinciones generacionales, sin por ello dejar de considerar los comportamientos de características transgeneracionales en cada contexto.

\section{HACIA UNA PERSPECTIVA GENERACIONAL EN EL ESTUDIO DE LAS SUBJETIVIDAdeS POLÍ́tiCAS. PROPUESTA CONCEPTUAL}

En una línea dialogante con los contenidos de los puntos 1 y 2, he desarrollado una propuesta de abordaje generacional en estudios sociopolíticos, la que se expone en dos libros publicados (Muñoz, 20062011), un artículo (Muñoz, 2008) y un proyecto en curso. ${ }^{7}$ Tal enfoque releva particularmente el factor relacional e identitario en la constitución de imaginarios generacionales, y fue construido a partir del estudio de algunas experiencias de movimientos socio políticos estudiantiles en la historia reciente de Chile y México. La idea ha sido abordar el tema de las culturas y subjetividades militantes (lógicas de acción, discursos, percepciones, horizontes, imágenes identitarias de los «nuestros»y los «otros», y autocomprensión en la historia por parte de organizaciones socio políticas, ya fuesen partidos, movimientos o corrientes) en vinculación con la construcción identitaria de lo generacional (el modo en que la socialización política vivenciada durante el periodo juvenil constituye una referencia para la articulación identitaria de imaginarios de generación que, en tanto imagen de un «nosotros» en la historia, fundamentan y justifican el accionar de los sujetos). Para tales investigaciones fue necesario sistematizar conceptualmente lo generacional, tarea que se desarrolló en diálogo con lo

quince años, establecidos en consideración del cumpleaños número treinta del ex presidente Eduardo Frei Montalva (1941), al que considera «epónimo» de una generación decisiva (Fuenzalida, 2003).

7 2010-2013. Proyecto posdoctoral FONDECYT: «Imaginarios generacionales, culturas políticas y cambios en las prácticas militantes. Un estudio de subjetividad política en la militancia PS y UDI (1980-2010)». Sociología, Universidad de Chile. 
que las propias investigaciones fueron arrojando. De cierto modo, el concepto generación orientaba las investigaciones al tiempo que era construido desde las mismas. A grandes rasgos, los principales contenidos de la mencionada propuesta fueron:

a) La historicidad de las generaciones o la ausencia de un ritmo predeterminado. Las generaciones no tienen un ritmo predeterminado con raíz en lo biológico, sino que la irrupción y cambio de generaciones depende de la vivencia sociohistórica y de la interpretación subjetiva de tal vivencia; es decir, de las marcas epocales, la memoria y la identidad.

b) La no centralidad metahistórica de las generaciones. Se considera lo generacional como una perspectiva que tiene valor en su comprensión con la gama de factores y condiciones que intervienen en una problemática sociohistórica, pues la generación no sería una meta categoría sobre determinante como la asumiera Ortega y Gasset.

c) La generación como una categoría asociada a lo moderno. El surgimiento de identidades generacionales está más presente si en periodos breves cambian los sistemas culturales, no así en sociedades más estáticas; es decir, la generación se encuentra particularmente asociada a la vertiginosidad creciente de las sociedades modernas.

d) La generación como categoría no absoluta en su vínculo con lo coetáneo. Asociado con su carácter moderno, la complejidad creciente de estratificaciones, roles y campos de acción de las sociedades, diversifica y particulariza los ámbitos de identificación generacional. En virtud de ello, se asumirán las generaciones como construcciones identitarias tan diversas como lo son las sociedades modernas y contemporáneas, y que por tanto, no pueden constituir una caracterización de homogeneidad de los coetáneos.

e) La flexibilidad de un concepto de generación o la generación como problema. En el concepto de generación, su unidad es su carácter de problema constante, el problema del recambio social que ocurre a partir de, por una parte, el hecho biológico de los nacimientos, desarrollos y muertes de los seres humanos, y por otra, el hecho sociohistórico de la conflictiva construcción de sociedad. Es tal problema de las generaciones, como lo planteara Mannheim, y no una naturaleza de la generación, lo que constituye una herramienta lo suficientemente flexible, al tiempo que potencialmente clarificadora, para el análisis de las sociedades desde una perspectiva social etaria.

f) La generación como construcción identitaria a partir de la juventud. La generación se asocia a una representación y auto representación de los sujetos respecto a la complejidad social y epocal que 
vivenciaron a partir de sus periodos de juventud. En ello, se entenderá la juventud como una edad social que involucra momentos fundantes de conciencia e interpretación del mundo; es decir, un periodo clave en la «estratificación de la vivencia» que planteara Mannheim.

g) La juventud como eje simbólico de lo generacional. Se coincide con las reflexiones de Martín Hopenhayn en el sentido de que «sólo se empieza a hablar de generaciones en sentido cultural cuando la juventud pasa a ser el símbolo y el ejecutor del cambio, de la diferenciación respecto de la generación precedente» (Hopenhayn, 2007:5). Es decir, se entiende que la generación se constituye como una referencia importante, cuando la juventud emerge como carga simbólica del cambio histórico, factor ideológico propio de las sociedades modernas.

h) La constitución relacional, identitaria y diferenciadora de las generaciones. Se considera central el cómo las identidades generacionales, a partir de sus interrelaciones - «encuentros», a decir de Salazar y Pinto-, construyen representaciones y valoraciones que nombran a «los nuestros» y a «los otros», fundamentando, desde ellas, sus propias perspectivas de acción. Es decir, se sostiene que aquellas imágenes que los sujetos construyeron respecto de las «otras generaciones», son fundamentales para la articulación del «nosotros generacional» (Muñoz, 2009-2011).

i) La gradualidad en las configuraciones generacionales o la existencia de generaciones de enlace. Cuando las marcas históricas han cambiado de forma abrupta, ocurre que jóvenes que viven su periodo de adolescencia o temprana juventud en el momento en que los cambios se desencadenan, viven intensamente la transición de un antiguo contexto a uno nuevo y por tanto, alcanzan a establecer identificación con la generación marcada por lo que concluye, al mismo tiempo que internalizan identitariamente, desde su juventud, los elementos del nuevo orden social simbólico. Tales «generaciones de enlace» (Salazar y Pinto, 2002), suelen actuar como nexos entre los ejes identitarios de la antigua generación y las identidades generacionales que se construyen plenamente en torno a las nuevas marcas históricas, trasmitiendo memoria y cumpliendo un papel importante en las nuevas lecturas de realidad y constitución de referentes de acción social (Muñoz, 2006).

j) Las generaciones como representaciones ideológicas. La «generación» puede aparecer también como una representación ideológica que define a las juventudes de una época, reforzando determinada idea, 
apuesta o proyecto relativo a un presente y/o devenir. Se trata de «imágenes de generación» como prototipos de juventud de un determinado contexto, discursos relativos a los jóvenes que los representan como portadores de «esperanzas» que potenciar o «amenazas» que combatir (Muñoz, 2003). El estudio de las generaciones es también, en este sentido, una forma de abordar tal construcción ideológica y discursiva.

k) La generación como categoría de análisis determinada por el análisis mismo. En la historia y las ciencias sociales, el investigador nombra la «generación» como referente de su análisis comprensivo, siendo ésta, en parte, fruto de su propia creación. Es decir, la existencia de generaciones y la amplitud o restricción de su tiempo y espacio, dependen, en parte, de la mirada analítica sobre ellas.

l) Lo generacional como factor sustantivamente diferente de lo etario. Por último, es importante estar claros en que un enfoque generacional es dinámico e histórico, por lo que no basta para su desarrollo el establecer unidades de análisis por edad. Un análisis generacional no trata de las relaciones entre «los adultos o viejos» y «los jóvenes» en abstracto, pero tampoco en un sentido estático cual fotografía de un instante social. Lo generacional involucra necesariamente el factor procesual en la construcción social e histórica de las realidades etarias, por lo que los sujetos se entienden como portadores de una edad social mediada por su historia.

La intención de esta propuesta es contribuir a un debate que en el futuro nos permita hablar de una perspectiva generacional. Lo anterior no pretende orientar un conjunto de ideas que enmarquen de modo rígido futuros análisis y posiciones, sino aportar a una problematización que sirva de referente a futuros abordajes y estudios, esto a fin de que la producción de conocimientos en torno a generaciones y política tenga un punto común respecto al cual referirse y desde donde avanzar.

\section{POR QUÉ UNA PERSPECTIVA GENERACIONAL, POR QUÉ HOY, POR QUÉ DESDE MANNHEIM}

Llama la atención que siendo la obra de Mannheim el clásico sociológico más relevante respecto a la teoría de las generaciones, ésta no ha sido abordada en las emergentes reflexiones que tocan la problemática generacional. La omisión ha sido una constante de muchos años en Chile y Latinoamérica, en donde incluso se ha llegado a asociar mecánicamente enfoque generacional con la perspectiva de Ortega y Gasset, la que a mi juicio, no cuenta con las fortalezas de la obra de 
Mannheim para estudios de historia y sociología. A mi entender la relevancia de la obra de Mannheim para el análisis de estas problemáticas, tiene fundamentos históricos y epistemológicos.

En lo histórico, me parece que, desde la posdictadura (quizá, nuestra propia «condición post» que se conecta con las más globales de lo posmoderno, post guerra fría y lo post fordista keynesiano), han ocurrido cambios significativos en los factores que definen las distinciones al interior del espectro político. Uno de ellos, es que pierden relevancia los aspectos doctrinarios y, en cambio, se vuelve central la identidad propia en la historia reciente del país, entendiendo por ello el continuo y conflictivo sopesar entre renovaciones y tradiciones; pragmatismos coyunturales y valoraciones fundamentales. En tal proceso, han sido claves tanto las propias experiencias a partir de las primeras socializaciones, como las subjetivas representaciones de ellas, lo que Mannheim llamaría una dialéctica estratificación de lo vivido que determina la configuración de la conciencia, la memoria y la identidad histórica. Por lo anterior, no es de extrañar que improntas y debates generacionales abunden en aquellas culturas políticas que han debido asimilar las profundas huellas de la dictadura, la transición y su marco global.

En lo epistemológico, la perspectiva de Mannheim permite al estudio de lo generacional no sólo abordar las influencias históricas sobre los sujetos coetáneos, sino que también abrir la mirada al estudio de las subjetividades presentes en las conexiones y unidades generacionales. En esto último, lo político identitario conectado con los planteamientos sobre la estratificación de la vivencia, dejan un terreno fértil para abordar la generación como construcción de imaginarios; es decir, aquel proceso en que la articulación de la conciencia histórica de los sujetos une memoria, proyecto e identidad; llenando de contenidos un «nosotros» político y definiendo a las otredades. Esa dimensión del campo político y la militancia aparece como central cuando ya han pasado décadas desde que los diagnósticos de fines del siglo XX señalaban cambios profundos en el modo de construir y proyectar politicidad. A años de aquel contexto en que se habló de posdictadura y de una transición conducente a «algo», creo que la mirada generacional puede aportar a alumbrar ese algo que ya está ante nuestros ojos y aún no terminamos de comprender. La tarea reviste carácter de urgente pues la política se vuelve ajena y en cierta medida «envejece» en los marcos institucionales, mientras los movimientos sociales y en 
especial los movimientos juveniles, como el estudiantil del 2011, sí politizan lo social haciéndose cargo de las conflictividades y del malestar sistémico que ha sido arrastrado desde la posdictadura. De algún modo, si entendemos la política como «aquella conflictiva y nunca acabada construcción del orden deseado» (Lechner, 1990) ella aparece claramente en los conflictos y propuestas del estudiantado que se movilizó en el 2011, y en cambio, se muestra balbuceante en un debate parlamentario que hasta ahora ha eludido el conflicto y no ha generado propuestas contundentes en torno a los ejes cuestionados del orden social vigente (las conexiones establecidas desde la dictadura entre Estado-mercado y sociedad). Lo político desborda a la política, lo que requiere imperiosamente de un ajuste, pues se necesita consistencia institucional para que la politicidad social encuentre eco y se manifieste en cambios concretos que revitalicen la democracia. La política debe volver a ser ciudadana y los políticos no pueden seguir siendo representados como una «clase política» ajena a lo social. En esto, el problema es más profundo que la inclusión de los jóvenes, pues la desafección respecto de las instituciones representativas es transversal, aunque los indicadores más evidentes (inscripción en los registros electorales, por ejemplo) sean particularmente visibles en las generaciones de reciente socialización pública.

En definitiva, si para Mannheim, olvido, memoria y sucesión generacional eran necesarias para que la historia aconteciera; nuestro presente nos indica que olvido y memoria han jugado sus cartas en un vertiginoso acontecer, que no obstante su radicalidad, ha descuidado la inclusión de los ciudadanos, y de modo particular, de los más jóvenes. La desafección social respecto de la política es un problema que, sin reducirse al aspecto generacional, tiene en él una dimensión no menor, pues a nadie le caben dudas que en el sistema político y de representación, los de ayer, aunque ya no son los de entonces, siguen siendo, en gran medida, los mismos.

SANTIAGO (CHILE), AGOSTO 2011

RECIBIDO: AGOSTO 2011

ACEPTADO: OCTUBRE 2011

\section{REFERENCIAS BIBLIOGRÁFICAS}


BAÑo, RODRIGO y ENZO FALETTO (1992): «El apoliticismo: el factor generacional». Serie Estudios Políticos 25. Santiago: FLACSO.

LECCARDI, CARMEN y CARLES FEIXA (2011): «El concepto de generación en las teorías sobre juventud. Última Década N³4. Valparaíso: Ediciones CIDPA.

FUENZALIDA, EDMUNDO (2003): «Generaciones y cultura política en Chile». Perspectivas en política, economía y gestión, Vol. 6, №2. Santiago.

GARRETón, MANUEL ANTONIO (2007): Del postpinochetismo a la sociedad democrática. Globalización y política en el bicentenario. Santiago: Arena Abierta Debate, Random House Mondadori.

- (1994): La faz sumergida del iceberg. Estudios sobre la transformación cultural. Santiago: LOM/CESOC.

GONZÁLEZ, YANCO (2003): «Existieron una vez setenta y tres muchachos... Paramilitarización y militancia de las juventudes mesocráticas chilenas». JOVENes Nº19. México: IMJ.

INSUNZA, ANDREA y JAVIER ORTEGA (2007): «El recambio frustrado en la élite política». Revista UDP $\mathrm{N}^{\circ} 4$. Santiago: Universidad Diego Portales.

HOPENHAYN, MARTín (2007): «Nueva visita a la brecha generacional». Revista UDP N 4 . Santiago: Universidad Diego Portales.

JoIgnANT, ALFREDO y PATRICIO NAVIA (2003): «De la política de individuos a los hombres del partido. Socialización, competencia política y penetración electoral de la UDI (1989-2001)». Estudios Públicos Nº9. Santiago: CEP.

LECHNER, NolBert (1990): Los patios interiores de la democracia. Subjetividad y política. Santiago: FCE.

MADRID, SEBASTIÁN (2005): “¿Políticos de ayer, apáticos de hoy? Generaciones, juventud y política en Chile». En ClAUdia FuENTES y ANDRÉS VILlaR. Voto ciudadano. Debate sobre la inscripción electoral. Santiago: FLACSO.

MANNHEIM, KARL (2005): «El problema de la juventud en la sociedad moderna». En: Diagnóstico de nuestro tiempo. México: FCE.

- (1993): «El problema de las generaciones». REIS N62. Madrid: CIS.

MOYANO, CRISTINA (2010): El MAPU en dictadura. Santiago: Ediciones Universidad Alberto Hurtado.

— (2009): MAPU o la seducción del poder y la juventud. Santiago: Ediciones Universidad Alberto Hurtado.

Mouffe, Chantal (2007): En torno a lo político. Buenos Aires: FCE.

Moulián, TOMÁs (2004): De la política letrada a la política analfabeta. La crisis de la política en el Chile actual y el «lavinismo». Santiago: LOM.

MuÑOZ TAMAYO, VíCTOR (2011): Generaciones. Juventud universitaria e izquierdas políticas en Chile y México (Universidad de Chile-UNAM 1984-2006). Santiago: LOM.

_ (2008): «Padres ejemplares, padres traidores. El '68' del '86' y el '86' del '99' en los movimientos estudiantiles de la UNAM». Revista Nostro- 
mo $\mathrm{N}^{\circ} 1$. México: UNAM.

- (2006): ACU. Rescatando el asombro. Historia de la Agrupación Cultural Universitaria. Santiago: Editorial Calabaza del Diablo.

- (2003): «Imágenes y estudios cuantitativos en la construcción social de juventud en Chile. Un acercamiento histórico (2003-1967)» Última Década No20. Valparaíso: Ediciones CIDPA.

ORTEGA Y GASSET, JosÉ (1994): «En torno a Galileo». Revista de Occidente. Madrid.

- (1956): «El tema de nuestro tiempo». Revista de Occidente. Madrid.

SALAZAR, GABRIEL y JULIO PINTO (2002): Historia contemporánea de Chile V. Niñez y juventud. Santiago: LOM.

- (1999): Historia contemporánea de Chile l. Estado, legitimidad y ciudadanía. Santiago: LOM.

Toro Maureira, Sergio (2008): «De lo político a lo cotidiano: jóvenes y generaciones políticas en Chile». Revista de Ciencia Política, Vol. 28, $\mathrm{N}^{0}$ 3. Santiago.

VALDIVIA, VERÓNICA et al. (2006-2008): Su revolución contra nuestra revolución. Tomos 1 y 2 Santiago: LOM. 